www.jmscr.igmpublication.org

Impact Factor (SJIF): 6.379

Index Copernicus Value: 79.54

ISSN (e)-2347-176x ISSN (p) 2455-0450

crossrefDOI: https://dx.doi.org/10.18535/jmscr/v6i8.57

\title{
Depression, Anxiety, Perceived Loneliness among School going Adolescents- A Comparative Study between Hostellers and Day Boarders
}

\author{
Authors
Dr Nikhil Nayar ${ }^{1}$, Dr Madhusudan Deshpande ${ }^{2}$, Dr Sagar Mudgal ${ }^{3}$, Dr Renu Pandey
${ }^{1,3,4}$ Junior Residents, ${ }^{2}$ Professor of Psychiatry \\ Department of Psychiatry, Index Medical College, Indore, MP, India
}

Corresponding Author

Dr Nikhil Nayar

Email: nikhil.nayar173@gmail.com, 8521396566

\begin{abstract}
There is a common saying - "The wheel, that squeaks gets the grease". Depression among adolescents has been recognized as a major public health issue. The objective of this study is to determine the prevalence of anxiety and depression among school-going adolescents and to compare between hostellers and day scholars. The study is conducted among the school students in the age group of 11-17 i.e students from class 6 to class 11. The total sample size is 80, 40 hostelers and 40 day scholars. Scales applied are the UCLA Loneliness Scale, Screen for child anxiety related disorders (SCARED, child version), 11- Item Kutcher Adolescent Depression Scale: KADS 11. Appropriate statistical tool applied using SPSS 22.0. Chi-square test applied. Score of all domains are found to be higher among adolescents living in hostellers but significant difference has been found in the scores of Panic disorder and Loneliness. No significant difference has been found in SCARED, GAD, Seperation anxiety, Social anxiety, and School avoidance.
\end{abstract}

\section{Introduction}

It is a globally accepted fact that during adolescence a child goes through a lot of changes physically, emotionally and socially. These changes have a great impact on them; they can either make or break an individual. Living away from family for a specific period of time leaves some enduring experiences in the life of the students $^{(1)}$. Day scholars do have an advantage in shielding the child from the adverse effects of peer pressure and its resulting problems. Adolescents residing as Day Scholar or hostellers are socialized and natured in totally different situations. So it is expected that Day Scholar and hostellers situation can affect adolescent's emotional intelligence and various areas of adjustment. This research is an attempt to study and compare the psychological and behavioral impacts of hostel life and day boarders that can help the teachers and parents of students to overcome problems they face during this period.

\section{Aims and Objectives}

To study the prevalence of depression, anxiety, perceived loneliness among school going adolescents and also compare for the same between hostellers and day scholars. 


\section{JMSCR Vol||06||Issue||08||Page 344-347||August}

\section{Methodology}

- The study has been conducted among the adolescents in the age group of 11-17 i.e. students from class 6 to class 11 . Class 12 students were not included considering board examinations. The school selected was a private school with students from middle socioeconomic status.

- 40 students were hostellers and 40 students were day boarders, age matched. Both are from the same school.

- Only male children as there was no facility of female hostel

- Cross sectional study
- Scales applied are the UCLA Loneliness Scale, Screen for child anxiety related disorders (SCARED, child version), 11Item Kutcher Adolescent Depression Scale: KADS 11.

\section{Statistics and Results}

The average number of children having positive scores in the subcategories of SCARED and the mean of KADS and UCLA are listed. The group is considered as a whole and then frequencies with respect to two groups are listed. Chi square test is then applied to see for any significant difference.

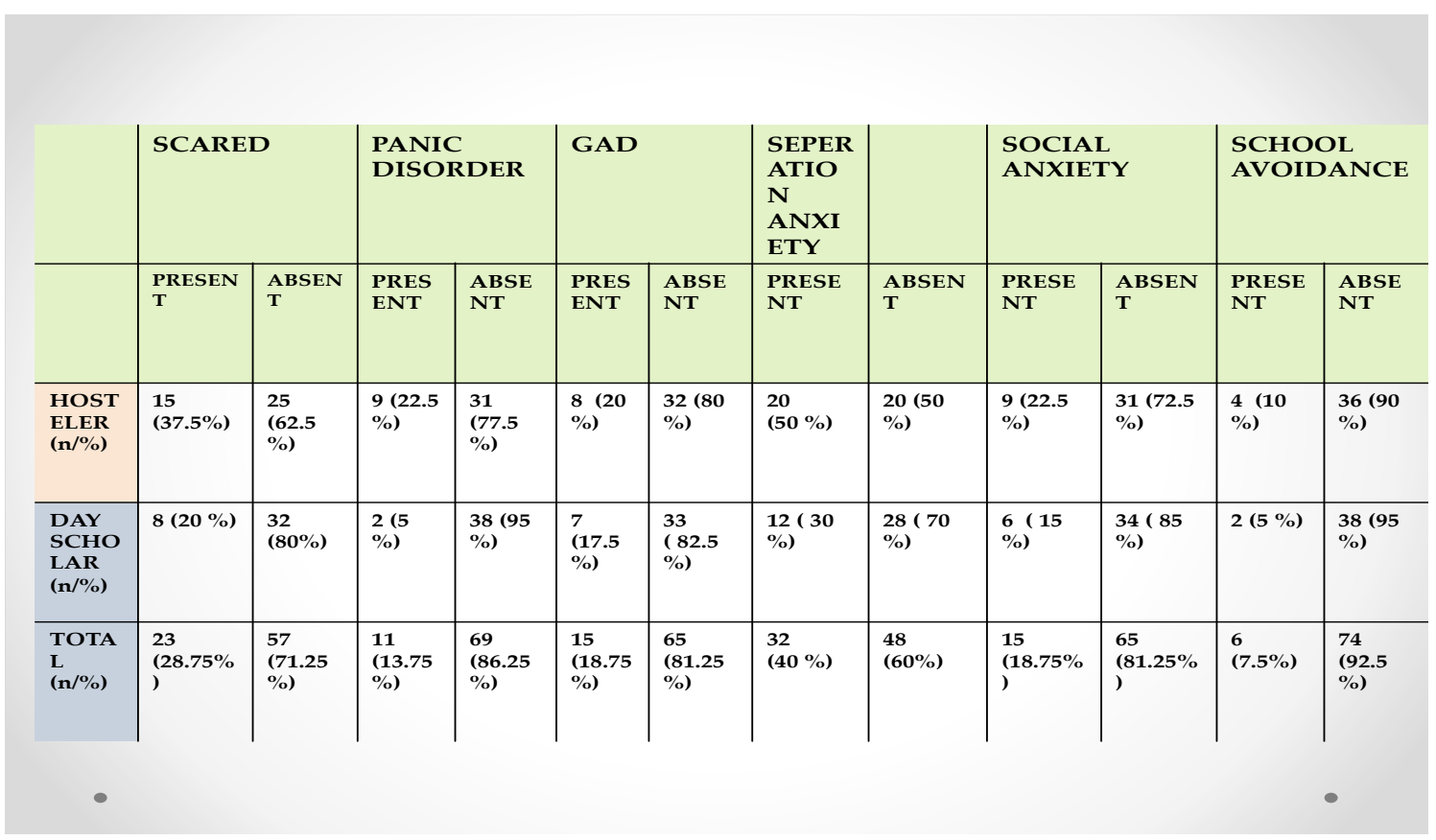

\section{Chi square test results}

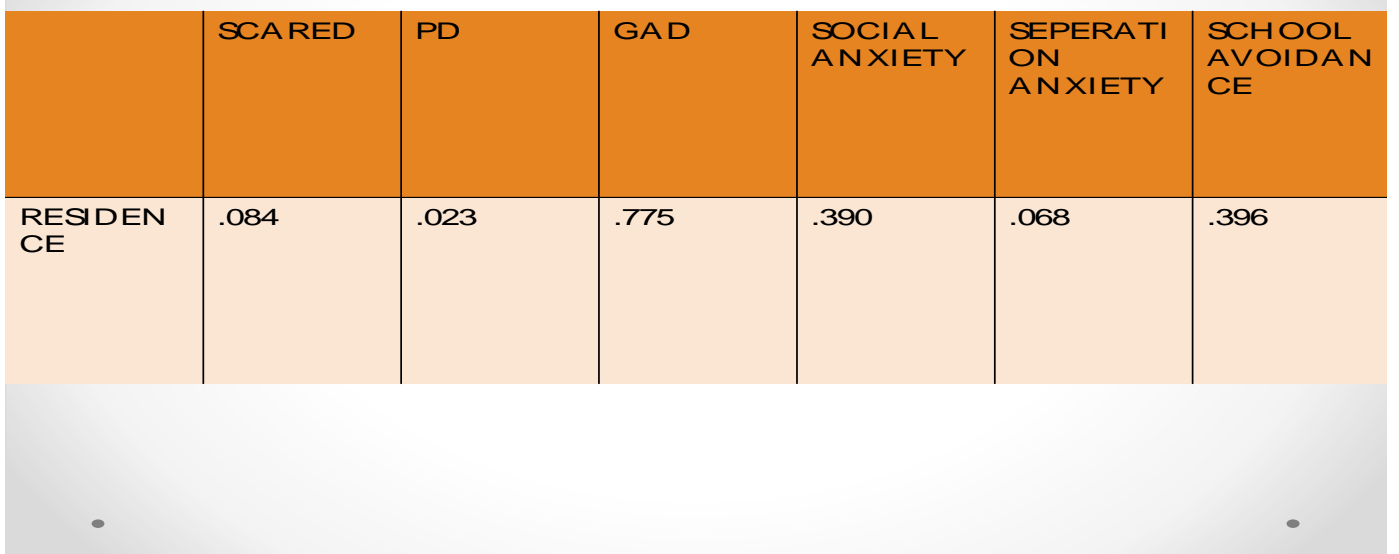




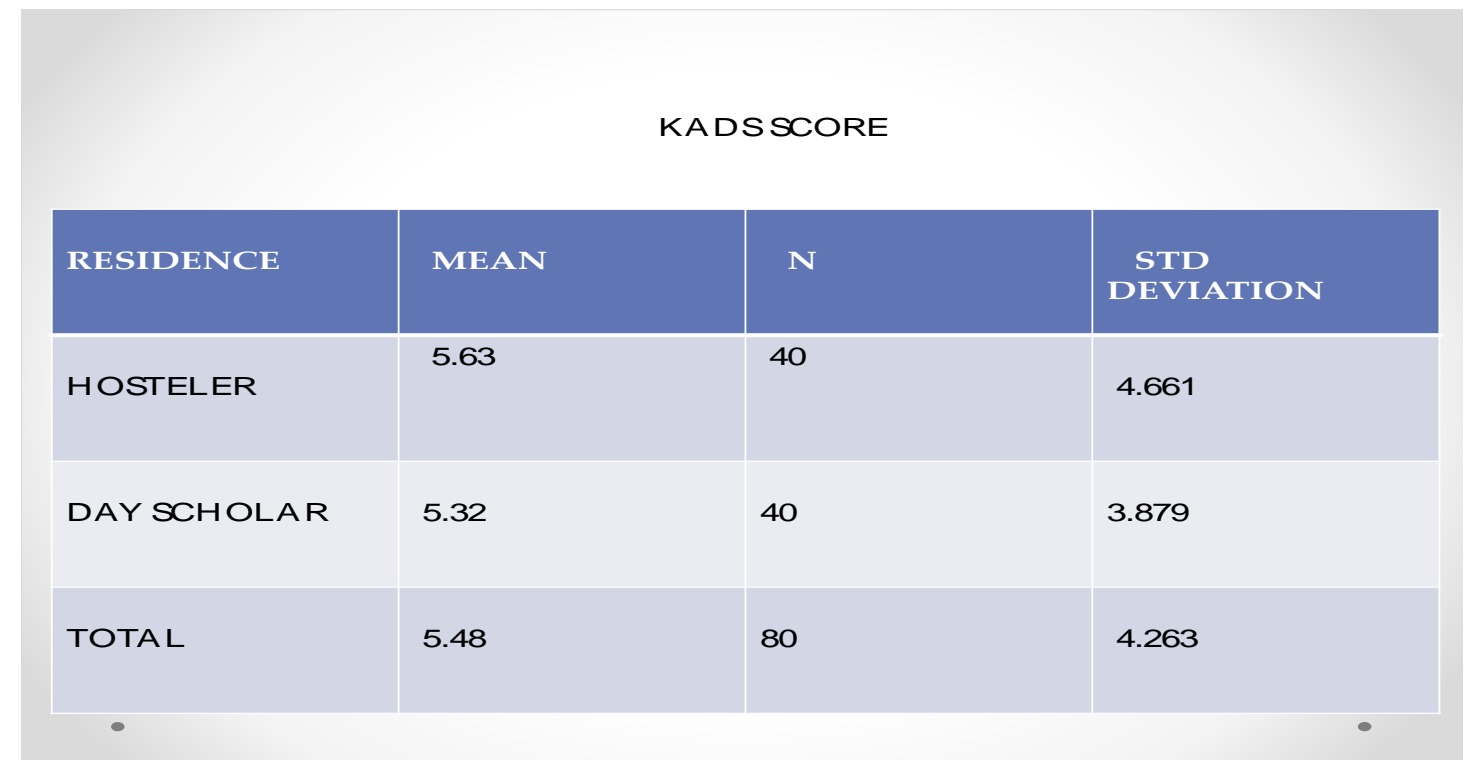

UCLA

\begin{tabular}{|l|l|l|l|}
\hline RESIDENCE & MEAN & N & $\begin{array}{c}\text { STD } \\
\text { DEVIATION }\end{array}$ \\
\hline HOSTELER & 32.50 & 40 & 7.602 \\
\hline DAY SCHOLAR & 26.58 & 40 & 6.480 \\
\hline TOTAL & 29.54 & 80 & 7.626 \\
\hline
\end{tabular}

\section{Discussion and Recommendations}

Score of all domains are found to be higher among adolescents living in hostellers but significant difference has been found in the scores of Panic disorder and Loneliness. No significant difference has been found in SCARED, GAD, Seperation anxiety, Social anxiety, School avoidance. Earnest efforts should be made targeting these students. Intervention strategies such as group activities, meditation, relaxation techniques, and extracurricular activities may be introduced to bring down the levels of stress, anxiety and depression among students. The study poses additional challenges for students' support services delivery, which may require addressing mental health problems along with common health strategies for the students. The study results warrant need for interventions like social and psychological support to improve the quality of life for the students. Student advisors and counselors may train students about stress management. Regular assessment of the mental health of the students should be incorporated. Scores of both the group is high, hence both the groups require intervention and revision of the counselling strategies at school level. But the hostellers need special attention and care considering the face that they are away from home and lack the stress sheilding effect of the parents. Living far away from family for a long time is a 
tough experience for young students. They have to strive hard to depend on themselves. Scientific literature also shows that parental support and family cohesiveness increase the chances of more positive outcome in academics ${ }^{(2)}$. Values, attitudes and expectations of parents/families keep influencing students, even in the physical absence of family member ${ }^{(3)}$. Social, psychological, physical and family problems of hostel students influence their learning ability and academic performance $^{(4)}$. In 2002, study by Gisele revealed that life in hostel is full of stressors that may harm judgment, concentration, self-esteem of students and cause anxiety and depression ${ }^{(5)}$. On the other hand, students dwelling in their own home might encounter different kinds of environmental factors that make them susceptible to anxiety.

\section{Limitations}

- Sample size (as only 40 students stayed in hostel, so total sample size could be 80 ).

- Only male sex, as female children are not staying in hostel currently.

- Socio economic status was not considered.

Ethical Permission: Institute ethics committee

\section{Conflict of Interest: Nil}

\section{Source of Funding: Nil}

\section{References}

1. Bronfenbrenner, (2007) U. Reaction to social pressure from adults versus peers among Soviet day school and boarding school pupils in the perspective of an American sample. Journal of Personality and Social Psychology.2007.15 (3), 179189.

2. Bowlby, J. (1973). Attachment and Loss: Separation (II). New York: Basic Books

3. Adams, G. R., Berzonsky, M. D., \& Keating, L. (2006). Psychosocial resources in first year university students: The role of identity processes and social relationships. Journal of Youth and Adolescence, 35(1), 81-91.

4. Chew-Graham, C. A., Rogers, A., \& Yassin, N. (2003). 'I wouldn't want it on my CV or their records': medical students' experiences of help-seeking for mental health problems. Medical Education, 37, 873-880.

5. Gisele, M. (2002). Stress in graduate medical degree. Medical Journal of Australia, 17, 10 - 11 . 